This item was submitted to Loughborough's Research Repository by the author.

Items in Figshare are protected by copyright, with all rights reserved, unless otherwise indicated.

\title{
Diagnostic formulations in psychotherapy
}

PLEASE CITE THE PUBLISHED VERSION

PUBLISHER

(c) Sage

LICENCE

CC BY-NC-ND 4.0

\section{REPOSITORY RECORD}

Antaki, Charles, Rebecca Barnes, and Ivan Leudar. 2019. "Diagnostic Formulations in Psychotherapy". figshare. https://hdl.handle.net/2134/2515. 
This item was submitted to Loughborough's Institutional Repository (https://dspace.lboro.ac.uk/) by the author and is made available under the following Creative Commons Licence conditions.

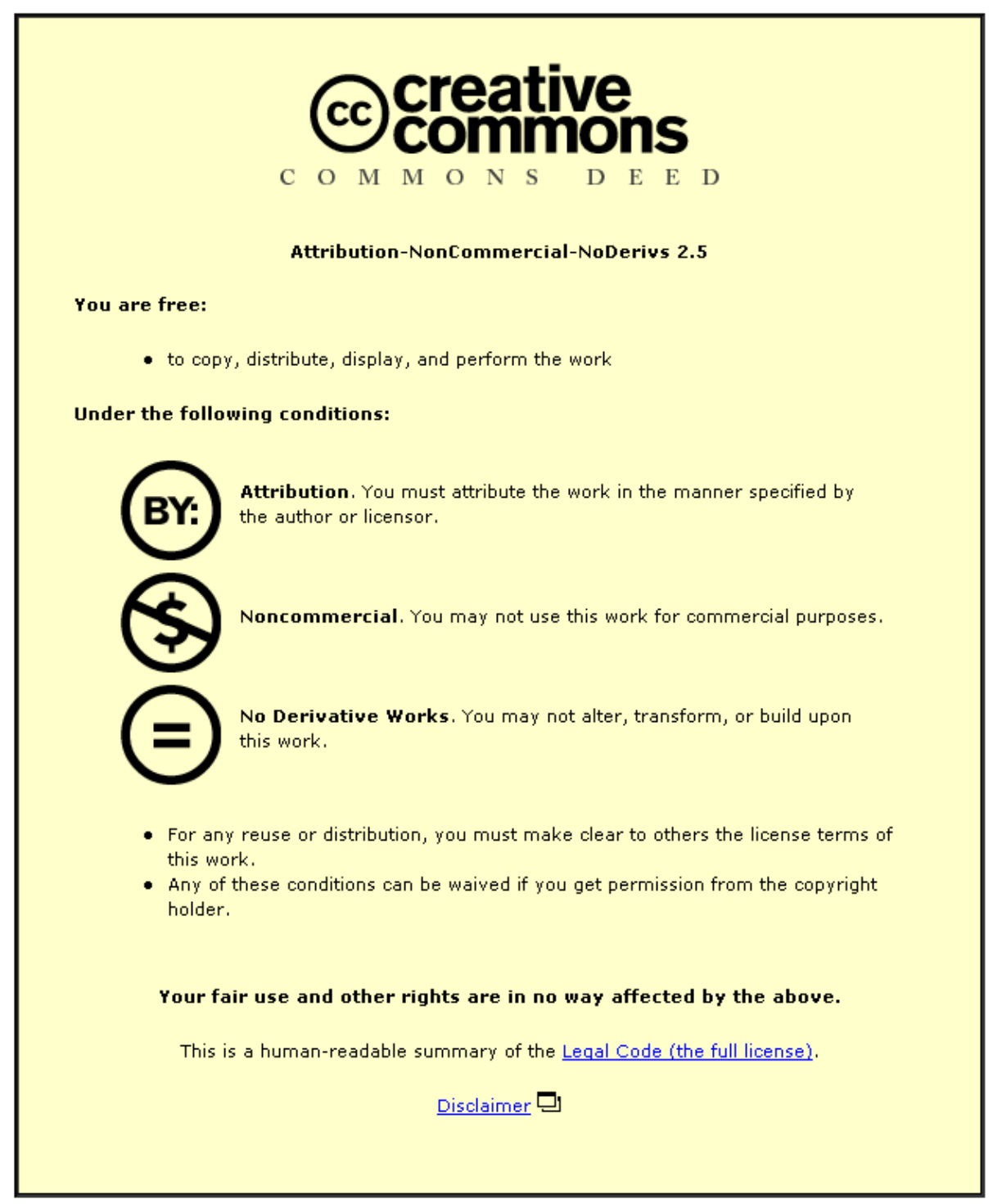

For the full text of this licence, please go to: http://creativecommons.org/licenses/by-nc-nd/2.5/ 


\title{
Diagnostic formulations in psychotherapy
}

Accepted for Discourse Studies, 7 (5) 2005.

Clean revision (filename: Diag forms Final Feb2505.doc)

\author{
Charles Antaki \\ Discourse and Rhetoric Group \\ Department of Social Sciences \\ Loughborough University \\ Loughborough LE11 3TU \\ England \\ c.antaki@Lboro.ac.uk \\ Rebecca Barnes \\ Research Fellow in Clinical Education \\ Peninsula Medical School \\ Room C315, Portland Square \\ University of Plymouth \\ Plymouth PL4 8AA \\ England \\ rebecca.barnes@pms.ac.uk \\ Ivan Leudar \\ Dept of Psychology \\ Manchester University \\ Oxford Rd \\ Manchester \\ M13 9PL \\ England \\ Leudar@fs1.fse.man.ac.uk
}

Suggested Short title: Diagnostic Formulations

Size: 9,446 words, $116 \mathrm{~KB}$

The research reported in this article was facilitated by ESRC grant number RES-000-220330 . 


\title{
Diagnostic formulations in psychotherapy
}

\begin{abstract}
Conversation analysts have noted that, in psychotherapy, formulations of the client's talk can be a vehicle for offering a psychological interpretation of the client's circumstances. But we notice that not all formulations in psychotherapy offer interpretations. We offer an analysis of formulations (both of the gist of the client's words and of their implications) that are diagnostic: that is, used by the professional to sharpen, clarify or refine the client's account and make it better able to provide what the professional needs to know about the client's history and symptoms. In doing so, these formulations also have the effect of shepherding the client's account towards subsequent therapeutic interpretation. In a coda, we notice that sometimes the formulations are designed discreetly. We examine one such discreet formulation in detail, and show how its very ambiguity can lead to its failure as a diagnostic probe.
\end{abstract}

Key Words: Conversation analysis, psychotherapy, institutional talk, formulations, gist, upshot, discreet talk 


\section{$\underline{\text { Introduction }}$}

Garfinkel and Sacks' classic 'On formal structures of practical actions' (1970) identified, amongst other things, the 'practical action' of formulating. The idea is that people can offer each other a way of understanding what they are both jointly doing. This can be brought about by describing their own or each other's actions or talk in a formulation, or summary phrase. Heritage and Watson (1979) noted that the practice was basically formatted as a conversational adjacency pair, with a preference for agreement. That is, if one speaker formulates what has just been said (either by summarising the gist of it, or by drawing out its relevant implication or upshot), then the other speaker is expected to take the opportunity to acknowledge that formulation, and to ratify it. Here is an example of an upshot formulation (lines 5 and 6), in which the interviewer draws out a relevant implication of what the interviewee has said.

Extract 1 (from Heritage and Watson, 1979: 134) Upshot formulation (arrowed) (I=interviewer; $\mathrm{R}=$ respondent)

1 I If occasion -if occasion 'rises again will you take similar

2 action?

$3 \mathrm{R}$ Well we have never hesitated so far to er take action where

4 er freedom is being abused.

$5 \rightarrow$ I So there might be another occasion on which you will use the

$6 \rightarrow \quad$ law against unions.

7 R Not necessarily against unions but against any body or which has

8 become over mighty er and is abusing its responsibilities er if that

9 happens to be a trades union so be it but we're not I repeat not

10 er looking out er for trouble to bash the trades union er the unions

11 have their proper role to play and I believe that to be not in the

12 political field

The interviewer's upshot formulation in the arrowed lines ("so there might be another occasion on which you will use the law against unions") draws out an implication from 
the interviewee's words. Notice that this is resisted by the interviewee ("Not necessarily against unions..."). Equally, the interviewer might have used a gist formulation to summarise what the original speaker had said, and that may also have turned out to be unwelcome. Such troublesomeness in a formulation is not of course inevitable; although a gist formulation must delete, select and rephrase what has been said, and an upshot formulation must extract an implication from the surface of what is said, the original speaker may accept such reworking without demur. We tend to see contentious formulations, according to Heritage (1985), more in institutional than in non-institutional interaction. Drew (2003) has suggested that this is because the interests of ordinary conversationalists are not normally served by leading or tendentious accounts of each others' talk. But that does happen when people meet to transact business. A radio phonein, for example, is a 'natural' place for a formulation because there the host needs to distil the caller's original utterance into something topical, designed for a broadcast audience, and worthy of comment (see, for example, Hutchby, 1996). Or, to choose another environment from which Drew gives a telling example, the negotiator on one side of an industrial dispute needs to have a way of describing the opposition's proposals in such a way as to advance his or her side's own interests. In both these institutional cases the format of a formulation advances a presumptive or tendentious version of the other person's talk, even if the interests that the presumption serves vary from setting to setting.

The very fact that formulation can be tendentious - can offer a reading which is pregnant with interpretation, and not necessarily in tune with the original speaker's professed interests - suggests that its use might help the institutional objectives of psychotherapy. After all, psychotherapy is famously the 'talking cure', and it will be no surprise to see therapists work to transform the raw material of their client's talk, and get this transformation accepted by their client. Davis (1986) was the first to advance the idea that formulations are an economical way in which the therapist could do so. Indeed her point was that such a move was better termed reformulation, given the change it proposed. 
Here is an example, from our own data ${ }^{1}$, of such a reformulation, in Davis' (1986) terms.

\section{Extract 2. JP/ Ronnie 28/02/2000}

1 C: $\quad>$ yess=ah'mean it's $<()>$. want'n t'live inna $<$ day, $(>$ m'interpr'ting

$2 \quad$ innnat $<$ ) I $\uparrow$ want more freedom. (.3) > $>$ 'know $<$, like today:,

3 T: ${ }^{\circ}$ ye::s. ${ }^{\circ}$

4 C: but-

$5 \quad(2.4)$

$6 \mathrm{~T}:$ 个more freedom for what.

$7 \quad(.5)$

8 C: $\uparrow \underline{\text { er::m }}$ (.) to $\uparrow$ go sailing, to go walking, an to meet ${ }^{\circ}$ people

$9 \quad\left[(\text { I spose })^{\circ}\right.$

10 T: $\quad\left[\right.$ ah (.) ${ }^{\circ}$ ri- $^{\circ}$

11 C: $\quad$ (.) ${ }^{\circ}$ yes: ${ }^{\circ}\left[(\right.$.$) yeh ts- =\left[(\right.$ simple $)$ stuff really, $()>.^{\circ} \mathrm{erm}^{\circ}<$,

12 T: $\quad\left[{ }^{\circ}\right.$ right $^{\circ} \quad[$ right

13 T: yes:. (.4) .h well- h- y- you can $\uparrow$ have all those thin:gs, (.3) but

14 at the moment your ( ) (serves a) different purpose

15 in your life.

$16 \quad(1.3)$

$17 \rightarrow \mathrm{T}:$ it's- (.) $\uparrow$ tha- (.) what you're saying is that when you get your life

$18 \rightarrow \quad$ sorted out, (.3) you want to $\uparrow$ fill the day, with things you (love)

$19 \rightarrow$ doing.

$20 \quad(.5)$

$21 \mathrm{C}:{ }^{\circ} \mathrm{yes}^{\circ}=$

The client wants the freedom to go sailing, to go walking and to meet people; the therapist's gist formulation recasts this in life-planning and emotional terms. What he is saying (according to the therapist) is that when he gets his life sorted out, he wants to fill the day with things he loves. In other words, the therapist finds in the client's list of 
pleasures an underlying psychological policy. The therapist is exercising her psychotherapeutic 'professional vision' as Hutchby (2004) puts it (after Goodwin's analysis of professional vision as a general resource for occupiers of institutional roles: see Goodwin, 1994). She is using her expertise to ' bring knowledge to bear, [display] the ability to categorise, see the relevant significance' (Schegloff, 1972, p. 92). It is a sort of 'instanced fixing' (Heritage \& Watson, 1979) which is exhibited for the client and requiring the client's reception. If the client accepts the therapist's formulation (and acceptance is the structurally preferred response), the therapist has succeeded, not just in summarising the client's words but in transforming the his experience.

Using talk to find the psychological in the mundane is the stuff of therapy. Indeed we might say that, for CA, formulations have been the royal road into the practices of psychotherapy. Peräklyä \& Vehviläinen (2003), for example, observe that formulations are a prime candidate for a CA reading of what the therapeutic community would call 'interpretation' and, to choose some representative examples of empirical work, we might note that Hak and de Boer (1996) have claimed that upshot formulations might be more serviceable for therapy than gist formulations; and both Madill, Widdicombe and Barkham (2001), and Antaki, Leudar, and Barnes (2004) have illustrated cases in which the adjacency pair format of formulation gives clients the opportunity (at some cost) of resisting the therapists' move.

In much of the CA writing on formulations, in therapy as on other forms of institutional an non-institutional talk, Heritage and Watson's useful distinction between formulations that summarise and those that draw out an implication has been to some degree blurred over. We shall come to discuss that later in the article. But for the moment we can proceed from Davis' basic observation, which remains the core idea in work on psychotherapy: that a formulation allows the therapist to propose a version of the client's talk which moves it in a therapeutically-oriented direction, in the sense of suggesting, as Peräklyä \& Vehviläinen put it "that the patient’s answers index an underlying mental pattern" (2003, p 739). 


\section{Getting the history, circumstances and symptoms}

Because psychological re-interpretation is such a canonical feature of psychotherapy, it is no surprise that that was where CA researchers first looked in their work on formulations. But formulations can do less vivid work in therapy too. This article is about one such kind of work, namely shaping the client's talk into hearably factual, recordable 'data' - not doing therapeutic intervention, but the diagnostic preliminary to any intervention, whether psychotherapeutic or any other.

Before we get to the formulations, it is worth establishing our claim that, in psychotherapy as in other institutional settings where there is a strong element of consultation (as, for example, medical consultation, an early field for CA research; see e.g. ten Have 1989), members do orient to establishing the premises on which the business will proceed - the facts, real or imagined, of the client's circumstances. The therapist will at some point do the business of 'getting the client's history straight' or 'getting a sense of what the problem is'. This is institutionally provided for at the start of the sessions, but may emerge interactionally at any time when (loosely speaking) there might be new material that wants describing or clarifying, or where some inconsistency emerges that throws previously established facts into question, and so on. We labour the point because when we get to see the diagnostic formulations, we need to have in mind that what they are formulating is information solicited as part of the history-taking aspect of the therapy session (that is to say, not oriented directly to the other, more 'therapeutic' aspects of the session, such as interpretation, advice, reassurance and so on).

Here is an example of an initial request for history and symptoms. It occurs at the very start of the first session between psychotherapist and client.

\section{Extract $3 \underline{\mathrm{SH} \text { and JR Session } 1}$}

1 Th. $\quad\lfloor>$ psychologist $<=. h \mathrm{~h}=\uparrow$ what I thought we'd do

2 toda:y, is just meet, find out what it was that you

3 wanted, $\uparrow$ in your $\uparrow$ own words. rather than me reading 


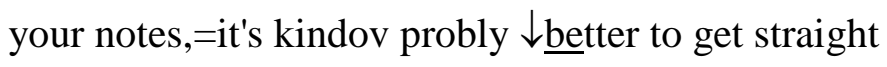

$5 \quad$ from $\lceil$ you

$6 \quad \mathrm{C} \quad \mathrm{Lye}^{\circ} \mathrm{a}: \mathrm{h}^{\circ}$

Again, before we get to formulations, here is another example of the therapist orienting to the need for getting the facts straight. We choose this example because it comes later in a session and shows how a therapist can signal that basic information, solicited earlier, is incomplete or deficient. In this case, the client had been explaining the onset of his illness. In an account that we do not show, but gloss as vague and hard to follow, he attributed the onset of his illness to some dealings he had with a barmaid, who was 'horrible' to him. The therapist takes this up.

\section{Extract 4CBT UV\&JR 110698}

1 T: In what way was she horrible to you.

$2 \quad(0.6)$

3 C: $\quad$ She she she's jus’ pressuring

$4 \quad \mathrm{~T}:$.hh

5 C: another chap said ('e's feelin' it) as well

6 Th: 'e w’s after 'er as well th'w’s a few act'lly

$7 \quad$ after 'er as well=

$\square \longrightarrow \mathrm{T}: \quad=\mathrm{SO}: \mathrm{O}$.hh I’M I’M A $\uparrow$ BIT con:fused about it 'cos

$9 \quad$ I'm not sure what wh:at what the pressure was about (.)

10 .hhhh there's a $\uparrow F E W$ of you after her

11 C: Yeh

The therapist receipts the client's account with an expression of dismay (I'm a bit confused about it) as a repair, abandoning what would have been a so-prefaced formulation; the abandonment signals that she does not even have enough raw data even to essay a version of what the client means. Confessing to being 'a bit confused' works to signal what comes next as a request for clarification ("I'm not sure what the pressure was about"). The client does not take up the opportunity of clarifying at the possible TRP after "about". The therapist's inbreath (".hhhh") perhaps works to mask the deficiency, 
and she herself immediately offers a candidate answer (Pomerantz 1984). She suggests that the client had had to deal with rivals for the barmaid's attention (there's a few of you after her) which, implicitly, might have caused 'pressure' on barmaid or client. The client does not elaborate beyond a minimal yeh and the therapist pursues the issue in other ways. We need not pursue the extract; the point is to note it as an example that issues of clarification of the client's symptoms and circumstances, can crop up, as it does here, at any time in a session.

We showed these two extracts, before getting on to talking about formulations, as illustrations of the therapists' orientation to 'getting the facts straight' as a preliminary to further work in the session, be it exploring alternative understandings of the events, delving into their causes, or figuring out routines for change ${ }^{2}$. But the point we want to make is that what the client comes up with in reply to questions about their history or symptoms is not always treated as sufficient by the therapist; it may be hearably incomplete, confused or otherwise deficient, in the therapist's terms. As in Extracts 3 and above, the therapist can ask for clarification outright or indeed provide a candidate answer. Or, as we shall now go on to see in the rest of this article, the therapist may use the format of a formulation explicitly to offer the client an informative redescription of what he or she has been saying.

\section{Therapy-leaning Diagnostic Formulations}

We shall see that, in our data set, the therapists use both gist and upshot formulations to propose diagnostically-relevant versions of what their clients say. The two formats are not perhaps so separable as they seem, as we shall see, but where there are clear examples of one or the other we shall signal them, and speculate on their specific characteristics. The main line of our argument, however, is what they have in common, namely the resource they afford the therapist in recasting inchoate, ambiguous or deficient information in a form which tends towards further psychologising of an institutional sort.

We start with an upshot formulation. The therapist is getting the history of the client's experience of 'visions' ${ }^{3}$. 


\section{Extract 5 RS \& AB session 1}

1 Th right. .h are things $\uparrow$ better at your mum and ${ }^{\circ} \mathrm{dad} \mathrm{s}^{\circ}{ }^{\circ}$ (.) in terms

2 of your $\mathrm{j}-\mathrm{d} \uparrow \mathrm{y}$ not get as many of th' $\uparrow$ visio:ns.

$3 \quad(1.2)$

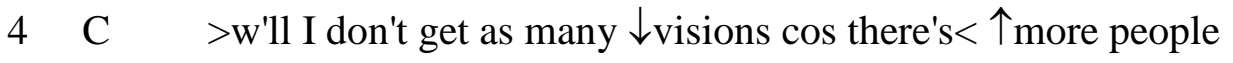

5 to $\uparrow$ tal:k to, more things to $\uparrow \underline{\mathrm{do}}$

$\square$ Th $\quad$ so $\uparrow$ that happens most when yer: (.) on your $\downarrow$ own, an' y' got

$7 \rightarrow \quad$ nothing to do.

$8 \quad(1.2)$

9 C ye:h.

The therapist is merely getting the client to list the circumstances of the appearance of these visions - he is not at the moment, apparently, interpreting them, or digging into their meaning and so on. He asks the client to confirm that when he is at his parents' he does not suffer the visions. The client confirms this. Note however, that the therapist does not merely accept this and move on - he pulls out, in an upshot formulation, the same information now as an account of when the client does get them ("so that happens most when you're on your own"). This draws out into the open the individualised, 'mental' nature of the problem, and of a correspondingly individualised and 'mental' line of therapy and treatment. The gist formulation, finding a natural or logical implication of what the client has just said, is an ideal vehicle for bringing out the elements of the situation which imply institutionally-provided for, therapy-implicative, diagnosis ${ }^{4}$.

This is a useful illustration of the main theme of our analysis: that even within what are designedly diagnostic formulations - here, a description which picks out, in an upshot formulation, the 'facts of the matter' - the therapist nevertheless has the opportunity to shape the client's experience in a way that can lead on to more canonically therapeutic business.

Is this also true of formulations that summarise, rather than draw out implications? We find that it is. Here is an example in which the therapist recasts the client's earlier 
description of a 'vision' that he had had that past week ${ }^{5}$. The upshot does clarify the basic diagnostic fact at the centre of the client's situation, but, as above, it also introduces the potential for subsequent psychologising work.

\section{Extract 6 CBT TU\&HD 261098}

$1 \quad \mathrm{~T}: \quad$.hh $\uparrow$ what $\uparrow$ sense d'you $\uparrow$ make of it

3 T: 'bout what it was all about (0.5) what started it

$4 \quad$ off an (1.2) an why this happens

$5 \quad(0.7)$

6 C: Ah don’t kn:ow (1.8) (fuckin’) why it=happens

7 T: 'Cos we did look at this theory of $\uparrow$ stress didn’t

8 we about um hallucinations being linked to how

$9 \quad$ stressed you were

10 C: Yeh

11 (3.5)

$\square \rightarrow \mathrm{T}$ : D'y'th- I'm n't- are you saying you think it was

13 the argument with yer Dad

14 C: Ye:ah $\uparrow$ I would think so yeh

In the extract above, the therapist abandons what might be a question as it were from her side ("d'ya think...") in favour of a formulation ("are you saying that..") which offers the client his own words back (see footnote 5). What his words, in the therapist's formulation, now contain is an explicit causal candidate for why the hallucinations started: "it was the argument with your dad". (Note the unusual emphasis on "with", which, to British English speakers, conveys the notion that the argument with the father had already been established, as reported by the client). This replaces the client's professed ignorance (line 6) and pulls out, from his previous report, the implication of a hearably psychological state of affairs - family conflict, father-son argument and so on - which would be material for therapeutic interpretation. 
The shaping towards subsequent work is still more explicit in this last example of this section. Here the therapist is working within the Cognitive Behaviour Therapy (CBT) framework, in which sessions are conducted in distinct phases. The first phase requires the therapist and client to agree a list of problems, which will be tackled in a later phase. Before the start of the extract, the client has been explaining her problems with getting to sleep, and has elaborated her account into a consideration of the effects of her medication. We join the talk after this account has gone on for a little while.

\section{Extract 7 SH\&JR 1}

1 C and $\uparrow$ but- (.3) I was told by the $>$ see pee en $<\left(\left(C P N^{6}\right)\right)$ don't

2 take them after six o'clock (.) $\left({ }^{\circ}\right.$ th'r $\left.^{\circ}\right)$ slightly ${ }^{\circ}$ stimulant ${ }^{\circ}$

3 but doc(.)tor (.) Fayra=ma gee pee ((GP)) w's say'n nah

$4 \quad$ they're not a stimulant they're m- (.) a $\downarrow$ side effect pill.

$5 \quad(.5)$

6 C so $\uparrow$ yesterday I took- erm- (.7) ah- (.) I $\uparrow$ got up at-

$7 \quad().(--)=\operatorname{took}(--)=$

8 Th $=\mathrm{mm}$

9

10 C took one at: em: two o'clock, 「an' that's- (on::)

11 Th L个mmm.

13 C ${ }^{\circ}$ seven $^{\circ}$ o'clock y'see:

$14 \quad(.5)$

15 C .pt an' $\lceil$ that- $(.) \mathrm{y}-\mathrm{s}=\uparrow \underline{I}$ don't=n- wh' that's stimulant or

16 Th $\quad{ }^{\circ} \mathrm{mm}^{\circ}$

17 C $\uparrow$ not (b' th' whther) (.) $\lceil(\quad$ )

$18 \rightarrow$ Th $\quad$.hh so: (.) $\uparrow \underline{\text { in general do you }}$

$19 \rightarrow \quad$ think that $\uparrow$ one problem is no bedtime routine.$h$ shall

$20 \rightarrow \quad$ we just $\downarrow$ call another problem (.) sleep (.6) generally,

21

22 C yea:「h 


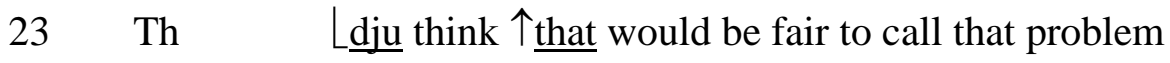

24 number two, (.3) to just write down (.) s:leep

The client's account has a number of 'therapisable' elements - topics that might be taken up for interpretation, reassurance and so on. But the therapist receives the client's talk with continuers (lines 8,16) or lets the turn pass (line 14). She overlaps the client's talk in line 17 with an audible in-breath, and loud so, such that her subsequent gist formulation is in the clear. It is a formulation that side-steps the possible issues of medication, the possible conflicts between different care-givers' advice, or the client's ways of coping with the side effects. Rather, it encapsulates the client's talk in a way that provides for closure and movement to next topic. It does so by recasting it as meeting an CBT agenda item, namely the listing of problems; hence the client's multifaceted account is recast as one problem which is no bedtime routine and another problem which we just call sleep generally. Although the formulation deletes the emotional and 'psychological' issues from the account, it makes it fit better the particular technical requirements of the therapy at this point.

\section{Diagnostic formulations of particularly distressing or graphic experiences}

The formulations above, while they progressed the business of the therapeutic harvesting of information, were occasioned by deficits in accounts of comparatively straightforward troubles. Psychotherapy clients' experiences, however, are often of a more distressing nature. Psychotherapy is normatively a setting in which distressing experiences can, and perhaps ought, to be frankly described. The therapists and clients in our sample certainly orient to that expectation, and formulations can be designed to solicit details about unpleasant experiences directly and graphically. Here is an example.

\section{Extract 8 CBT TU\&HD 261098}

1 T: $\quad>$ Oh right so it’s just even then $<(\underline{h})$ hhuh i(h)t's ju(h)st a n(h)ice

2 w(hh)ay (h)of .hh of $\operatorname{div}(\mathrm{h})$ iding i(h)t u(h)p .hh ${ }^{\circ}$ ri:ght then ${ }^{\circ}$

3 .hh right so we'll start with the homework and you were doing

4 um .h I'd asked you <if you > 
$5 \quad$ ((sound of pages being turned))

6 if you had er: (0.4) er hallucination (0.4) to write it down and

$7 \quad$ try and identify ${ }^{\circ}$ what had caused it ${ }^{\circ}$

$8 \quad(0.6)$

9 T: $. h h=$

$10 \mathrm{C}:{ }^{\circ} \mathrm{Yeh}^{\circ}$

11 T: which you've done. .hh u::m

$12(0.8)$

13 T: and this one here that hh it's er a vision that you had

$14 \quad(0.5)$

15 C: Ye[h

16 T: [So you said you're on yer bed in a room when the carpet

17 becomes loads of snakes (.) all wriggling about the ceiling

18 closes in on me (0.7) pushing me off the bed inta the

19 snakes $(0.7)$ they cover me and I come out of the vision.

$20 \quad(0.6)$

21 T: .pk so is there some of that is well (.) u:m: (1.4) actual

$\square 2$ feeling of the snakes on yer body as w[ell

23 C: [Yẹ:h

$24 \quad(0.5)$

$\square 5 \rightarrow$ T: So there's a: there's a tounch element $\underline{\text { as }}=$

26 C: =Yẹ:h=

27 T: =as well to it .hh when did that $\uparrow$ one happ:en

28 C: Last week

The client has done her homework ${ }^{7}$ in recording the distressing hallucination of 'snakes all wriggling about on the carpet and the ceiling closing in'. The therapist's intervention is formatted in a double-barrelled way: first a confirmation check, with only very light editorialising, in asking 'so is there some of that as well.. actual feeling of the snakes over your body'; then a gist formulation, nailing down the tactile aspect of the experience ("so there's a touch element as well"). 
Such a formulation is in the service of getting a full, if unsettling, picture of the extent of the client's troubles. In the case above, it rounds out the troubling extent of the hallucination. Still more diagnostic is the next example, where the therapist is checking whether the client suffers from symptoms which, in our culture, we might recognise as 'paranoia':

Extract $9 \mathrm{RS}$ and $\mathrm{AB}$ session 1

1 Th.

L个how do all these

2

people know that you've had $\uparrow$ er (.) $>$ sort of mental $<\uparrow$ health

3 problem or (.) whatever.

4

5 Th. $\quad$ ohow d'they ${ }^{\circ}(.7)$ how do they $\uparrow$ know:

6

(.4)

7 C well I know (remember $\uparrow$ one) van that drives past me that's

8 (y'l b个uilders) .h (.4) a:n' 个they (thin' there buildin') to me

9 个ouse.

$10 \quad(.3)$

11 Th. ri:ght.

$12 \quad(1.4)$

13 Th. and when they were at yer house, did th- $\mathrm{f}$ - did you talk to

14 them or somethin, ${ }^{\circ}$ or? ${ }^{\circ}$

$15 \quad(.5)$

16 C No:, me $\uparrow$ mum did, but me mum talks to er-=bleedin' everyone

17 (tsat 've tol') (.5) t- (.4) told them all me $\uparrow$ business like I've been

18 in hospital $\lceil$ (all $\rceil$ times) and all this shit.

19 Th. $\lfloor\uparrow I$ see $\rfloor$

$20 \rightarrow$ Th. so $\uparrow$ people actually lean out of the $\uparrow$ windows when you go past ' $n$

21 (.6) shout ab个use at you.

22 C Tyeh.

23 Th. what sort of $\uparrow$ people just anyone in particular, or (.) c- (.4) .h you 
In line 18 the client extends his turn over the therapist's I see receipt of the client's announcement of his 'trouble' with his mother. His turn ends on $a n^{\prime}$ all this shit. However, the therapist does not orient to this invitation to assess the client's negative assessment of what his mother does. Instead, at 20-21 he offers a formulation of the client's experience of being harassed. The client seems to agree with the possibly paranoid idea that people in passing cars lean out and shout abuse at him. In what appears to be an institutionallyrelevant check of the reality of this possibly delusional beliefs, the therapist goes on to ask how often this happens (lines 23 onwards, with the subsequent pursuit of this line of questions not shown).

Such a direct expression of the client's diagnostically-relevant experience is to be contrasted with hearably discreet or euphemistic formulation. These seem to be ways of handling what would otherwise be a very distressing, raw or otherwise challenging descriptions. It is important to say that our notion of 'discreet' is a members' notion. In that sense we are in the same territory as Peyrot (1987) and Bergmann (1992). The difference is that, unlike those authors, we identify discreet talk (or circumspection, as Peyrot terms it) by dint of the comparison between the client's account and the therapist's immediately succeeding version. For Bergmann, discretion is visible in the rhetorical features of the talk itself (c.f. his example in which the psychiatrist, before hearing the client's account, solicits it as 'running across the street [not so completely dressed] or something like that'; Bergmann, 1992, p 149). We recognise the formulation as discreet in its designed comparison (through its sequential placement) to what is manifest or heavily implied in what the client has been saying.

For us, then, we see discretion by comparing the client's account with the therapist's version. Here is an example of a discreet formulation of the client's words. The client is describing what he hears from the 'voice'.

\section{Extract 10 AG\&HD session 1}


1 C $\quad$ b't it $\uparrow j^{\prime}$ st seem to be a $\uparrow$ nasty ${ }^{\circ}$ voi $^{\circ}-\underline{I}$ might feel a bit (.)

2 bit better, when soon's=I (.6) ㄹ $\uparrow y^{\prime} t-(1.0)>$ wunnit,

3 wunnit $<\uparrow$ wite (.) wite- $\uparrow$ why'it says summi' like er

4 (.3) (.) er ( $\uparrow$ bitch) or ${ }^{\circ}$ (tick $=$ or) summin' like ${ }^{\circ}$ at ${ }^{\circ \circ}>$ n'ye- $<{ }^{\circ \circ}$

$5 \quad$ (.4). $\mathrm{h} \mathrm{(.)} \mathrm{but} \mathrm{ee-} \mathrm{ee-} \mathrm{it} \uparrow$ does $(.)^{\circ}{ }^{\circ}{ }^{*}$ or dog or whatever* ${ }^{\circ}$

$6 \quad\left(\left({ }^{*}{ }^{c}{ }^{\prime} o_{k} y^{*}\right)\right)($.$) it's very er- it's menacing, \uparrow$ you know,

$7 \quad$ Th. $\quad{ }^{\circ \circ} \mathrm{m}::^{\circ \circ}=$

8 C =doesn't seem to:: er go away, (.5) ('n)'it's very nasty.

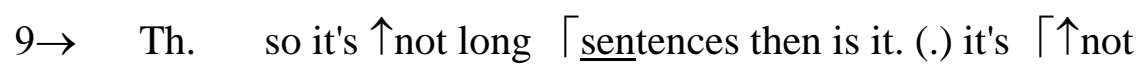

10 C L(yeh snog-) Lno

$11 \rightarrow$ Th. $\quad$ er (.3) it's saying the odd $\left\lceil\right.$ wo:rd ${ }^{\circ}$ and $^{\circ}($.$) re \uparrow$ peatin' it $\rceil$

12 C $\quad$ L $-\ldots$ s'm words and y'r 」eh)

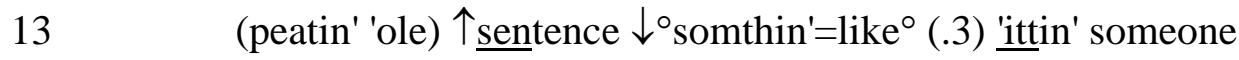

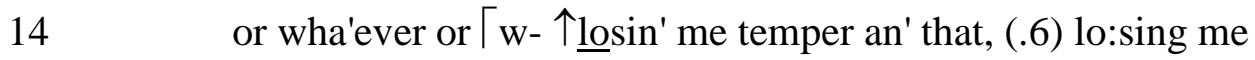

15 Th. $\quad\left[{ }^{\circ}\right.$ yeh $^{\circ \circ}$

16 C rag or something $\lceil$ (but it jus' has- tee-) $\uparrow$ it $\uparrow$ does .h $\uparrow \underline{\underline{a h w} \text { - ah }}$

17 Th. $\quad\left\lfloor{ }^{\circ} \mathrm{m}^{\circ \circ}\right.$

18 C w- the man' times I write down the (teams) it's that kind of $\uparrow$ thing. $19 \quad(.3)$

$20 \rightarrow$ Th. $\quad{ }^{\circ}$ yeah $^{\circ}().\left\lceil\underline{\text { so }}\right.$ you've been doing a $\uparrow$ lot of writin' $\downarrow$ down. (.) ${ }^{\circ}$ you

The therapist is taking the client's history and at this point the topic is the client's experience of hearing a voice. The client's description of what the voice says is often hard to make out, but where it is clear it is troubling: the voice is nastyand very menacing. The client allows a TRP at line 8, which would commit the therapist to orient to the description it's very nasty. Instead, she formulates the issue as being (merely) one of sentence length: it's not long sentences then, it's not er it's saying the odd word and repeatin $i t$. This is a hearably less troubling formulation. It is initially oriented to by the client yeh repeatin whole sentences but he adds more detail, again of a troubling sort: hittin someone or whatever or losing me rag (losing my temper). Again the therapist 
formulates this in a neutral way: yeah so you've been doing a lot of writing down. This puts discreetly what might otherwise have been horrible experiences. The institutional interests that this seems to serve is of keeping the descriptions 'non-therapisable' until this history taking phase of the session is complete. Discretion helps wash out the extraneous emotional colour from the information while still conveying a degree of relatedness to, and concern for, the client.

\section{When discretion may misfire}

On other occasions the discretion used in formulations may frustrate its institutional objective. This is the theme of our last analytic section. The cost of using a discreet and euphemistic formulation is that the client may orient ('deliberately' or not) to the more innocent of the readings such a form of words necessarily makes available. Here is an example, which is rather lengthy to bring out the diagnostic implications of the therapist's formulation. We begin at an early point in the proceedings, where the client is being asked to explain 'why he is here'.

\section{Extract 11 AG\&HD session 1}

1 Th and- (th' 't) $\uparrow$ ah've got to ask you all these $\uparrow$ questions=> wha(=I'll

2 'slly=do'n is) erm- (.4) is get the person to ${ }^{\circ}$ jus- $^{\circ}$.h (.) tell me what's

$3 \quad$ happened to them (.) what- what- $\uparrow$ what's the $\downarrow$ problem what's

$4 \quad \downarrow_{\text {wrong. }}$

$5 \quad \mathrm{C}$ yeah

6 Th and what's happened to them in the $\uparrow$ past you know $\uparrow$ get

$7 \quad\lceil$ some idea

8 C Lri:gh-

9 Th about (.5) what it's like being ((Firstname $\uparrow$ Surname))=what you've

$10 \rightarrow \quad \quad$ been through and (.3) how on earth did you end up $\lceil$ today $=$

11 C Lrigh- L.hhh

$12 \rightarrow \quad$ Th $\quad=$ sittin' in $\lceil$ (ward)

$13 \mathrm{C} \quad \mathrm{L}(($ cough $))$ 
14

15

$16 \rightarrow \quad$ Th

$17 \quad \mathrm{C}$

18 Th
(.5)

.h $\lceil\uparrow$ righ-

Ltwenty $\uparrow$ two, (.) $\Gamma^{\circ}$ tal'in'o $^{\prime o}$ to $\uparrow$ me $\lceil$ in this $\uparrow$ interview

Lyeh

$L^{\circ} \mathrm{mm}^{\circ}$

19

room. $=$ I $>$ don't know what would be the $<$ best place to start

The therapist invites the client to explain, then, how on earth he ended up today sittin' in ward twenty-two talkin' to her in this interview room. The specific reference to the particular ward and the interview room carries, in the hospital environment, the strong implications of accountability. Why is he in this specific ward? The particular membership category of "Ward 22" will be relevant in his formulating a response (Schegloff, 1972). It puts him under some obligation not just to describe his troubles, but also to account for why they have caused him to end up in this particular, diagnosticallyinformative, place.

For reasons of space we have to leave out what he says, as it covers many pages of transcript. Our gloss is that his account of how he had 'ended up' here is confusing (he is unspecific in the identification of people and places, the chronology is difficult to follow, events seem to be conflated, and some parts of the account seem to be narratives from a separate domain). During his account the therapist's contributions have been largely limited to continuers. Eventually she offers a set of formulations, progressively more tendentious, designed to bring out the answer to the question about his appearance in this ward. It is the last of these which is the one that 'misfires', but we need to see how the therapist works up to it.

First, the therapist orients to one element of the client's complex account which refers to his upcoming residential accommodation. She offers an upshot formulation of what the client had been saying about where he would be accommodated. 
Extract 12. AG\&HD session 1 (from the same interaction as Extract 11, but some 20 minutes later in the session, after $\mathrm{C}$ has responded to T's invitation to explain how he has 'ended up' here)

$1 \mathrm{a} \rightarrow$ Th. $\quad$ so- $\mathrm{y}^{\prime} \uparrow$ not going back to (.) $\uparrow$ is it $\uparrow\left(\right.$ Tow $\left\lceil\right.$ ers House) ${ }^{\circ}$ you (- - -)

$2 \mathrm{C}$

Lwell (.) I'm going back

3 to it but=

4 Th. =uhhuh $=$

5 C = =y'know (.) be- I f'l better I feel more (.6) $\uparrow \underline{\text { calm }}$ in meself 'n that

6 so- (1.1) y'now I'm (all - - I thin'), hh (.) (more - - -,) so (.)

$7 \quad$ it won't be so much like er an effort to (.5) cope. (.3) so much.

$8 \quad(.3)$

$9 \quad$ Th. will that same $\uparrow$ person be there (.) th't=er $\lceil(--)$ you had (=

$10 \mathrm{C}$

Lyeh he'll be there, yeh

11 Th. =- - -) an that

12 C Iyeh, he'll be there.

The client confirms that he is going back to a certain unit ("Towers House"), and, orienting to the standing issue of his mental well-being, claims that he will cope better this time. The therapist follows up question with will the same person be there that er you had ( ) an that. This discreet reference to 'the same person' is not occasioned in any immediately past co-text, but refers back to a point, embedded much earlier in the client's account, in which he described a violent incident with a fellow resident ${ }^{8}$. The therapist's question, though it avoids actually pronouncing what it is the did (he kicked the fellow in the face) makes it relevant as a possible factor in his possible reception at Towers House. The client confirms that this person will be there, and the interaction continues with a further formulation:

Extract 13 (follows directly on from Extract 12).

$13 \mathrm{~b} \rightarrow$ Th. $\uparrow$ you $\uparrow$ think that's going ta be $\uparrow$ difficult going back=

$14 \mathrm{C}=$ yeh it'd $\uparrow$ be

$15 \rightarrow$ Th. $\quad$ lea- $\uparrow$ living with $\uparrow \underline{h i m:::}$ 
17 C well (.) he ju' ignores me half the time.

$18 \quad(.4)$

19 Th. ${ }^{\circ} \mathrm{mhm}^{\circ}$

20 C $\quad$ so er (1.3) (>well's $\uparrow$ om 'any<) (.) ${ }^{\circ} \mathrm{er}=\uparrow$ not very ${ }^{\circ}$ nice not $\mathrm{w}^{\prime}$

21 v'y friendly so (.3) hh but'll just have to stay out of his $\lceil\uparrow$ way.

The therapist proposes that the client will find it difficult going back to Towers House and living with this person. Notice again that she discreetly avoids specifying what this difficulty consists in - that the client has previously kicked one of the residents in the face. The client nevertheless orients to this aspect of the situation, and replies that although this person is not very nice or friendly, he'll just have to stay out of his way.

So far we have seen therapist and client orient to the issue of where the client is accommodated, and its corollary how he will cope there, especially given that there is another resident there who will make it difficult. All this is pertinent to establishing his current state and circumstances. But it does not actually answer the hanging question as to how or why he has ended up here in Ward twenty two. The therapist now makes that question operative in her next formulation, apparently abandoning the discretion she has so far been showing.

Extract 14 (follows directly on from Extract 13)

22c $\rightarrow$ Th.

$$
{ }^{\circ \circ} \mathrm{mm}^{\circ}
$$

23 $\rightarrow \quad$ 个so are you $\uparrow$ saying that you ended up $\uparrow$ here because you hit $24 \rightarrow \quad$ this person who had y'at court and w'z (.5)

Let us look in detail at this summarising formulation. On the face of it, you ended up here because you hit this person who had you at court is no euphemism. It seems to squarely state that the client is there because he hit someone who then took him to court. In what sense is this formulation nevertheless discreet? In three senses. Firstly and most obviously, "you hit this person" is a terminological euphemism: it still avoids using the 
more graphic and violent description given by the client himself - that he kicked him in the face. Secondly, the formulation is discreet is that it specifies a particular victim - this person who had you at court - implying a one-off episode which resulted in a court appearance not because the police or mental health authorities took an interest but because the victim himself "had you at court". The third way it is discreet is in avoiding spelling out the fact that criminal violent conduct could well mean that one 'ends up' in a psychiatric ward involuntarily, as a consequence of a court order under a section of the Mental Health Act. That is to say, the therapist glosses the fact that the client might be here because he has been judged to be so mentally ill and dangerous to himself or others as to need incarceration.

All that is an illustration of how to design a diagnostic formulation discreetly. But the thing we want now to notice is that discretion has its cost. See how the client responds to the therapist's formulation:

Extract 15 (follows directly on from Extract 14)

25 C $\uparrow$ nu:- that w'z- $\lceil$ that w'z a different guy, yeah, that was

26 Th. Lt-

27 C was a different ${ }^{\circ}$ guy $=\mathrm{th}^{\prime \circ} \mathrm{w}^{\prime} \uparrow \underline{\text { two }}$ of 'em (.7) $\lceil$ the'w's the $\rceil$ one

28 Th. $\quad{ }^{\circ}$ uhh right $\left.{ }^{\circ}\right\rfloor$

$29 \quad(.3)$

30 C Notty- er (.4) $\uparrow$ Barry was the one ee- (.5) er (1.2) shout'ee

$31 \quad$ ab $\underline{u s e}^{\circ} \mathrm{er}^{\circ}$

The client orients to the identity of the person who took him to court - nu:- that $W^{\prime} z$ that $W^{\prime} z$ a different guy. In doing so he picks out (deliberately or not we cannot say) a diagnostically unimportant reading of the event, frustrating the therapist's institutional objective of getting on record that he ended up here by court order. From the therapists' point of view, whether he hit this person or that is irrelevant to the need to know whether the client has been referred to her under the provisions of the Mental Health Act, as 
someone who poses a danger to himself or others ${ }^{9}$, and whether he has enough insight to be aware of the fact. For therapists, then, a discreet formulation can be 'misunderstood', and misfire exactly because of its studied avoidance of the most direct approach to getting the desired diagnostic information.

\section{Concluding Comments}

The study reported here adds to our understanding of psychotherapy as a site for the negotiation of versions, a field of research which has attracted interest in CA since Sacks's pioneering work on group therapy (among other interactions, of course) in his Lectures on Conversation (Sacks, 1992). We set out to explore how formulations could work to promote a certain psychotherapeutic objective, namely, to help establish the 'facts of the matter' of the client's life-history, their symptoms or their circumstances. We found that formulations could supplement questions either at the start of the therapeutic encounter or at any point where the client's provision of information is deemed correctable or improvable. The advantage that formulations have over questions in pursuing information is that they offer, or seem to offer, the clients' own words back to them, or, in the case of upshot formulations, to extract a helpful implication from what the client has said. That is, they seem to respect the normative assumption that therapy should 'hear' the client. This might be signalled explicitly (as in what you're saying is...) or strongly implied by the conjunction so. In either case, the format of offering a paraphrase, or of drawing out a natural implication, masks the non-neutrality of the therapist's description.

The tendency of the formulations we analysed was towards shaping the client's accounts in one of two therapeutically-relevant ways: to serve the management of the session, or to establish a bridge to the more overtly interpretative elements of the therapists' subsequent interventions. With regard to the session's management, we saw the formulation select out of the client's account (which might be quite complicated) material that was hearably 'streamlined'. In one case, for example, a client gave an involved account of having trouble sleeping due to the effects of medication about which she had been given conflicting medical advice (an account that this description inadequately summarises, of 
course; see Extract 7 for the client's own words). The formulation offered by the therapist

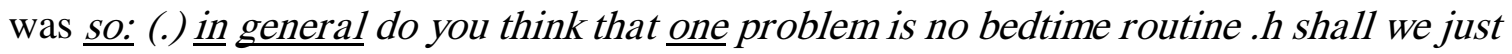
call another problem (.) sleep (.6) generally. The formulation smoothes down the experience to fit the currently-relevant institutional objective of 'making a list of the client's problems'. In such cases, formulations demonstrate to the client that their words are being heard, while at the same time getting on record a version which deletes elements which the client may nevertheless consider to be therapy-relevant. They serve in the management of the therapy session (the proper ordering of information before interpretation, for example) which is the responsibility of the therapist, but may not figure so largely for the client, or may indeed be alien to the client's conception of what therapy should be about (c.f. Peräkylä and Vehviläinen, 2003 on the therapy interaction as theorised by the therapist).

The other interests that we saw formulations serving was providing for a potential transition between history-taking and the ostensibly more psychotherapeutic work of interpretation, without actually counting as interpretation itself. In such cases, the therapist selected out of the client's account an element which strongly hinted at a certain psychological reading. For example, in Extract 6 the client was offering information about the onset of his hallucinations, and the therapist formulated his words as are you saying you think it was the argument with yer Dad. This description is heavily implicative of grounds for interpretation of the hallucinations in terms of parental conflict.

We noted that formulations in therapy had sometimes to handle very distressing experiences. In some cases these could be treated robustly, but we also noted that formulations allowed the therapist to recast graphically vivid material into something more neutral. However, here we saw that the very discretion of the formulation could allow the client to overturn the therapist's institutional project, by orienting to the more innocent of the alternative readings the formulations offered. We reported a case in which the therapist, pursuing the institutionally significant information of whether the client had been sent involuntarily for therapy ('sectioned' in British parlance), offered him the 
formulation that he had ended up here because you hit this person who had y'at court. The client, we saw, oriented not to the heavy implication that he had been sectioned, but the 'irrelevant' (to the therapist) issue of just who it was he had hit: nu:- that $W^{\prime} z$-that $W^{\prime} z$ a different guy. We used this example to illustrate that even apparently highly tendentious conversational moves such as formulations can be misunderstood, resisted, or evaded.

There are two issues we would like to end with. In a moment we will broach the question of therapists' own appreciation of the service to which they put formulations. First, it is worth revisiting the distinction we made, at various points throughout the article, between formulations which summarise and those which draw out an implication. Students of conversation analysts' handling of formulations since Garfinkel and Sacks will know that there has been a mutation, and to some degree a respecification, of their original concept; it was, of course, meant to refer to something more like an observation of how the current state of interaction was to be described - not individual stretches of talk, as such. We speculate that this meta-pragmatic conception of formulation has been jettisoned in part because such things, although significant when they occur, just are not very frequent. Heritage and Watson's (1979) more empirically grounded account allowed formulations to be conceived of as versions of what was said in a more literal way - as formulations not of the state of play of the interaction, but of the previous speaker's actual or implied words. That has been extremely productive, as the frequent reference to formulation in (and outside) the CA literature testifies. But it is the case that posterity has not fully respected the distinction that Heritage and Watson usefully proposed between what they called gist and upshot formulations.

Certainly a case can be made that this distinction wants revisiting and clearing up, although at base it seems to us that there is a useful distinction to make between a version of events that summarises another's words and one that draws out some (allegedly) natural implication from them. Nevertheless it seems that in the wider usage of the term in the CA literature and around it, a 'formulation' has come to mean - in its most permissive usage - any commentary by one speaker, in whatever format, which may be taken to propose or imply a reworking of events described or implied by a previous 
speaker. The CA literature on psychotherapy is no exception to this blurring of the distinction. Indeed, among the research we have reviewed, only Hak and de Boer (1996) make much of the difference between gist and upshot formulations; and even they (to our eyes) proceed with a very lax criterion for what will count as one kind or the other. But this is not the place to enter into a detailed account of the issue. We have tried in the article to be clear about which sort of formulation the therapist was using (when it was possible to separate them, which in our case was on most occasions). Had there been a clear association between upshot and gist on the one hand and the interactional usage on the other, then we would have made more of the distinction; as it is, both types seemed to be used in much the same way, so we contented ourselves only with specifying which formulation it was in each extract, and leaving possible functional differences to come out in some later inspection.

Now the issue of therapists' own accounts of what they do with formulations. We follow the line suggested by Peräkylä and Vehviläinen (2003) who note that CA can elaborate on, and provide detail about, therapists' 'stocks of interactional knowledge' - their own members' theories about their interactional practices as therapists. Peräkylä and Vehviläinen also observe that CA's commitment to open-minded exploration of interaction without commitment to pre-existing theories also means that CA can discover practices about which members themselves may be silent. Our speculation is that while therapists are quite clear that they have routines which they use to extract facts an basic data from their clients, they may not be aware that they use formulations in this way, possibly because formulations are so closely associated, in our cultural view of therapy, with psychological interpretation. This must remain speculation ahead of commentary from the therapeutic community. But if so then this may represent an addition to their 'stock of interactional knowledge' and count as a contribution that CA may make back into professional practice. 


\section{$\underline{\text { References }}$}

Antaki C. , Leudar I and Barnes, R. (2004) Trouble in agreeing on a client's problem in a cognitive-behavioural therapy session. Rivista di Psicolinguistica Applicata. 4, 127-138

Bergmann J R (1992) Veiled morality: notes on discretion in psychiatry. In P Drew and J Heritage (eds) Talk at Work Cambridge: Cambridge University Press.

Boyd, E.A \& Heritage, J. (in press) Taking the patient's medical history: Questioning during comprehensive history taking, In J. Heritage and D.W. Maynard (Eds.) Practicing Medicine: Structure and Process in the Primary Care Encounter. Cambridge, UK: Cambridge University Press

Buttny, R. (1996). Client's and therapist's joint construction of the client's problems. Research on Language and Social Interaction, 29, 125-153.

Davis, K. (1986). The process of problem re(formulation) in psychotherapy. Sociology of Health and Illness, $\underline{8}, 44-74$.

Drew, P. (2003) 'Comparative analysis of talk-in-interaction in different institutional settings: A sketch'. In Studies in Language and Social Interaction: In Honor of Robert Hopper, P.J. Glenn, C.D. LeBaron and J. Mandelbaum (eds.), 293-308. Mahwah, NJ: Erlbaum

Garfinkel, H., and Sacks, H . (1970). On formal structures of practical actions. In: McKinney, J.C., and Tiryakian, E.A. (Eds.) Theoretical sociology. Appleton- CenturyCrofts, pp. 337-366

Goodwin, C (1994) "Professional Vision." American Anthropologist 96(3): 606-33 
Hak, T and de Boer, F (1996) Formulations in first encounters. Journal of Pragmatics, 25, 83-99.

Heritage, J. (1985) Analyzing News Interviews: Aspects of the Production of Talk for an Overhearing Audience. In T.A. Van Dijk (Ed.), Handbook of Discourse Analysis, Vol. 3, (London: Academic Press).

Heritage, J.C., D.R. Watson, (1979) Formulations as conversational objects. In: George Psathas, ed., Everyday language: studies in ethnomethodology. New York: Irvington: 123-62

Hutchby, I (1996) Confrontation Talk: Arguments, Asymmetries and Power on Talk

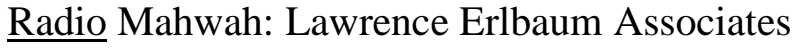

Hutchby, I (2004) "Formulations in the interaction between counsellors and young children”. Conference on Conversation Analysis and Psychotherapy, Manchester University, Manchester, England.

Madill , A, Widdicombe, S and Barkham, M (2001) The potential of conversation analysis for psychotherapy research. Counselling Psychologist 29, 413-434

Peräkylä, A. \& Vehviläinen, S. (2003) Conversation analysis and the professional stocks of interactional knowledge. Discourse \& Society 14 (6): 2003

Peyrot, M (1987) Circumspection in psychotherapy - structures and strategies of counselor-client interaction. Semiotica, 65, 249-268

Pomerantz, A. (1984). Pursuing a response. In J. M. Atkinson \& J. Heritage (Eds.), Structures of Social Action. Studies in conversational analysis (pp. 152-163). Cambridge: University Press. 
Pomerantz, A (1986) Extreme case formulations: A way of legitimizing claims. Studies, 9 , 219-229.

Pomerantz, A. 1988. Offering a candidate answer: an information seeking strategy. Communication Monographs 55:360-373.

Sacks, H (1992) Lectures on Conversation. Oxford: Basil Blackwell

Schegloff, E.A. (1972). Notes on a conversational practice: Formulating place. In D. Sudnow (Ed.) Studies in social interaction (pp. 75-119). New York: Free Press.

ten Have, P (1989) The consultation as genre. In B. Torode, ed. Text and Talk as Social Practice . Dordrecht/Providence, R.I.: Foris Publications (1989): 115-35 -

Vehviläinen, S (2003) Preparing and delivering interpretations in psychoanalytic interaction. Text, 4, 573-606 


\section{$\underline{\text { Bio notes }}$}

Charles Antaki is Reader in Language and Social Psychology at Loughborough University's Department of Social Sciences, where he is a member of the Discourse and Rhetoric Group. His research interests are in Conversation Analysis, especially as it illuminates identity, therapy and the communication of people with learning disabilities.

Rebecca Barnes is a research fellow in the Institute of Clinical Education at the Peninsula Medical School, Universities of Exeter and Plymouth, England. She has studied the organisation of interaction in a range of contemporary institutional contexts: problembased learning in adult education, interprofessional meetings and psychotherapy.

Ivan Leudar is a Reader in Psychology based at the School of Psychological Sciences, The University of Manchester (leudar@man.ac.uk). His recent work includes the book 'Voices of Reason, Voices of Insanity' (Routledge, 2000), special issue of Theory and Psychology on 'Theory of Mind' (coming out October 2004), as well as on history of insanity (History and Psychiatry, 2002) and the way we think of the past (History of Human Sciences, 2002). He is also a practicing visual artist. 


\section{$\underline{\text { Endnotes }}$}

${ }^{1}$ Our data come from about nine hours of Cognitive Behaviour Therapy offered, by three different therapists, on the British National Health system, and about the same amount of eclectic, humanistic therapy by a private practitioner. We treat the data set as a whole.

${ }^{2}$ We have two bases for our claim that such information about history, circumstances and symptoms normatively precedes the therapeutic work. One is our general members' understanding about what psychotherapy ought to mean - that intervention or treatment must be sensitive to, and be contingent on, the client's particular problems as the client her or himself expresses them. The other is that the therapists themselves provide ample evidence that this is so; as in Extract 3 they may signal the initial history taking explicitly as something they 'have to do', and as in this example:

\section{$\mathrm{RS}$ and $\mathrm{AB}$ session 1}

Th: $\quad$.hh erm (.3) $\uparrow>$ yeah<- I $\uparrow$ wanted. hh to just go over things=again just t- to double check things a bit (.) $\uparrow$ em .pt (.6) $\uparrow \uparrow c ' n$ you tell me a bit ab $\downarrow$ out $=>$ you were saying about the voices and the $s-<$ things that you see $=$ can you just tell me a little bit $\uparrow$ more about that you so I've- $j^{\prime}$ I've just got it for ce: $r^{\circ} \operatorname{tain}^{\circ}$ ?

They may also signal the end of the history-taking phase as a preliminary to the more active work of therapy, thus:

CBT UV\&JR 110698

Th: $\quad$ Right $\uparrow$ what I thought we'd spend the rest of the time doing is now I've got a picture of what's going on .hhh shall we draw up what I'm gonna call a problem lis:t and from that we'll draw a goal lis:t 
3 The reader will see that a number of our examples come when the client is describing experiences such as hearing voices. This is because half our cases come from a publichealth Cognitive Behaviour Therapy clinic set up to attend to a range of clients including those diagnosed as having schizophrenia.

${ }^{4}$ One might say that the therapist's summarising formulation is simply a positive version of the client's negative account. But it is significant that there is a pause of 1.2 seconds before the client responds with a minimal agreement. If nothing else, this shows that the client sees some difference between the therapist's account and his own. A possible reading is that the client may be signalling a rather reluctant acceptance of the therapist's version, and the line of diagnostic reasoning it implies.

5 Therapist and client had been going through the client's 'homework' diary for that week. Here, in rough transcript, is the client's account that gets (some brief moments later) formulated in the extract shown in the body of the article.

T: Can you tell me what was $\uparrow$ happening at the time

C: Well I'd just had an argument with me Dad and I was a bit stressed out $=$

T: Yeh=

$\mathrm{C}: \quad=$ an I went up to me room to play on the Playstation .hh

T: Yeh

C: when I got a blinding headache and knew I had to lie down cos I had a vision coming on

${ }^{6}$ C.P.N.: Community Psychiatric Nurse. The reference, two lines later, to "ma G.P." is to the client's general practitioner. 
${ }^{7}$ In Cognitive Behaviour Therapy, clients are routinely expected to keep daily records of distressing events and of the success of techniques which they have been trained to use to lessen them.

${ }^{8}$ This stretch comes from the client's account of his recent history. Notice that he specifies that he kicked someone in the face.

C I I was tryin' ${ }^{10} \mathrm{ve}^{\circ}$ a lot of $\uparrow$ patience with 'im hh (.) $\uparrow$ er keepin' me $\uparrow$ temper an (alsud'n=I) snapped.

C $\quad \uparrow a:: n d$ erm (.) (>end'd=up $<)($.$) ker kickin' someone in the$ $\uparrow$ face there, (.7) zis: er: this guy, (1.4) but $\uparrow$ e: ${ }^{\circ}{ }^{\prime}{ }^{\circ}$ (.) e- eekinda=like er (.) $\uparrow$ said somethin to me and somebody went (- - -) out o' me pocket, (.4) and he 'ad the $\uparrow$ jacket on, (.8) a:nd erm we:: (.4) (- - - - - - - -) I 'ad to the $\uparrow_{\text {social }}^{\circ}$ again $^{\circ}$.

C $\quad$ er (.) things like that $>=$ an 'e $\uparrow$ kept (wearin') me $<$ jacket, an I ggot (t've) a bit of a cob on. (.5) c's I wasn't $\uparrow$ feelin' too well at the moment (.7) and er just somethin I $\uparrow$ (stole) (er w's zis:) (.) los' me $\uparrow$ temper.

${ }^{9}$ It is worth reporting that the therapist does not pursue the point at this stage of the session. However, right at the end, she explicitly asks are you here under a section of the mental 个health act. 